\section{Viewpoint}

\section{Physics and Communications}

'For scientific research, communication is essential. The results of research only become scientific when they are published.'

A formidable array of physics periodicals have been established on the basis of this viewpoint. As the number grew, secondary abstracts publications and even more advanced systems were introduced to cope with the 'information explosion'.

However, despite this increasing abundance of literature in physics itself, there does not appear to have been corresponding success in communicating understanding of physics to the public. It is not only clear explanation of the results of research which are required - a task well within the competence of many articulate physicists - but also imaginative portrayals of the operational effectiveness of the physics research system.

At the Second General Conference of EPS earlier in October, well-formulated Plenary Lectures captured some of the most fascinating work in European physics. Although the Conference received some coverage from television, radio and newspapers in Fed. Rep. of Germany, it proved impossible to focus the attention of the public on the most rewarding fields of physics, on the changing emphasis on the role of physics and physicists in society, and on the continuing interdependence of physics and technology. The almost complete disregard by the media and the subsequent lack of response by the public should be a clear danger signal which flashes throughout the European physics community. It is essential that communication with the public be extended effectively, so that an appreciation of physics becomes a more significant aspect of European culture. How else is the physics research system to obtain the public support so essential to its well-being ?

\title{
Subnuclear physics and scientific culture
}

The Editor of Europhysics News reports on a visit to the International Centre for Scientific Culture, Erice, Sicily, on the occasion of the International School of Subnuclear Physics from 7-29 July 1972.

At the invitation of A. Zichichi, Director of the International Centre for Scientific Culture, the Editor travelled to Erice for two days. Apart from the technical content, the School presented the opportunity for students and lecturers to discuss the nature of science and its role in the world in an environment of history and beauty.

\section{International Centre for Scientific Culture}

Founded ten years ago, through the efforts of A. Zichichi, the Centre comprises 35 Schools, whose activities go on from March to October each year, and which range across the pure and applied sciences (including medicine and agronomy). Of these in 1972, no fewer than 18 courses aimed at the international scientific community. Amongst the most successful has

\section{Contents}

Viewpoint

Subnuclear physics and scientific culture.

Controlled fusion and plasma physics.

Selected problems in magnetism

Letter to the Editor.

The Research System .

Trends in Physics

Society News.

Meetings been the International School of Subnuclear Physics, directed by Zichichi himself, for which 400 applicants sought 100 places. The Centre sets out to attract the best lecturers and so can be highly selective amongst students.

Apart from the Schools with an international audience, the Centre has others in Italian for students from preuniversity level upwards. All courses are sponsored by the Regional Sicilian Government, the Italian Ministry of Public Education, and the Italian Ministry of Scientific and Technological Research.

Zichichi, who is Director of the Centre and has acted as Chairman of the High Energy and Particle Physics Division of EPS, was quite willing for Erice to be considered an established site for Europhysics 'Summer' Schools. The recommendation for establishment of such sites was contained in the paper 'A Guide to Europhysics Conferences' prepared by the EPS Advisory Committee on Conferences and published in Europhysics News 35 (June 1972) 1-4. The Quantum Electronics Division will hold their third course at Erice in 1973.

Erice is a quiet town situated on top of a coastal mountain and overlooks an extensive fertile plain and the Mediterranean Sea. It is easily accessible from Trapani airport or railway station, and by road and ferry from the Italian mainland. Although it is well off the main tourist circuit, Erice is magnificent and well worth a visit. Outstanding features are the two castles (Castle Venus and a medieval castle), the Cyclopean walls 